\title{
Comparing spectacle and toric contact lens prescribing trends for astigmatism
}

This article was published in the following Dove Press journal:

Clinical Optometry

\section{Byoung Sun Chu' \\ Mei Ying Boon ${ }^{2}$ \\ Dong Hwan Noh ${ }^{3}$}

'School of Optometry and Vision Science, Daegu Catholic University, Hayang-eup, Gyeongsan-si, Gyeongsangbuk-do, Republic of Korea; ${ }^{2} \mathrm{School}$ of Optometry and Vision Science, University of New South Wales, Sydney, Australia; ${ }^{3}$ DAVICH Optical Chain, Daechi-dong, Gangnam-gu, Seoul, South Korea
Correspondence: Byoung Sun Chu School of Optometry and Vision Science, Daegu Catholic University, I3-13 Hayang-ro, Hayang-eup, Gyeongsan-si, Gyeongsangbuk-do 38430,

Republic of Korea

Tel +82538502553

Fax +82533596793

Email bschu@cu.ac.kr
Background: The purpose of this study is to investigate and compare spectacle and contact lens (CL) prescription trends, with an emphasis on astigmatic refractive error prescribing differences for patients who purchase spectacles or CLs in South Korea.

Methods: A retrospective study of patient records of a major optical chain in South Korea was conducted. De-identified data of age, gender, power of prescribed spectacles and/or CLs were extracted from the practice database. Inclusion criteria were being within the first 10,000 purchasers of spectacles or CLs or both.

Results: The first 10,000 purchases comprised spectacles (59\%) and CLs (41\%) (male:female ratio 4:6). The proportion of purchasers who were female was significantly higher for CLs (88\% female, $12 \%$ male) than spectacles ( $43 \%$ female, $57 \%$ male) $\left(\chi^{2}=4480.36, d f=1, P<0.0001\right)$. There was a significant difference in the proportions of purchases by age group for spectacles and CLs $\left(\chi^{2}=3246.69, d f=3, P<0.0001\right)$. Spherical power distribution of prescribed lenses was similar between the groups; however, cylinder power and axis were significantly different $(P<0.0001)$. CL astigmatic powers were more likely to be $1.00 \mathrm{DC}$ or greater, whereas the majority of spectacle lenses had astigmatic power of $0.75 \mathrm{DC}$ or less. In total, $90 \%$ of toric CLs were prescribed $\times 180$ and $9 \%$ other meridians, unlike spectacles where $50 \%$ were prescribed $\times 180,14 \% \times 90$ and $40 \%$ at oblique meridians.

Conclusion: There is scope for providing increased toric lens correction amongst CL wearers and increasing the proportion of wearers who are male. The estimated gap for toric lens prescription amongst $C L$ wearers who have clinically significant astigmatism $\geq 0.75 \mathrm{DC}$ is about $59 \%$.

Keywords: astigmatism, toric contact lens, coverage, prescribing gap, spectacle correction, demographics

\section{Introduction}

Astigmatism is a refractive error that results in blurred vision due to the eye focusing incoming light to more than one focal plane, and so an unfocussed image falls on the retina. Optical correction of astigmatism includes spectacles or toric contact lenses (CLs). Estimates of population prevalence vary depending on the age range, population studied and the level of astigmatic refractive error defined as being clinically significant. In infants and toddlers, clinically significant astigmatism prevalence is estimated to vary from $24 \%{ }^{1}$ to $70 \% .^{2}$ In adults, prevalence rates range from about $50 \%$ to $95 \%$, with the highest rates found in the oldest individuals. ${ }^{3-5}$

South Korean rates of astigmatism are similar to rates observed in other countries $^{1,2,4-6}$ (Table 1); however, toric lens fits in South Korea comprised approximately 
$20 \%$ of CL fits, which is in the lower half of the countries that participated in a global survey of prescribing trends (which ranged from $6 \%$ in Russia to $48 \%$ in Portugal), ${ }^{7}$ suggesting that some prospective CL patients who need toric CLs may not be prescribed toric CLs, so have uncorrected astigmatism, or that spectacle wearers who are astigmatic may be less likely to wear CLs than spectacles in South Korea. If such a mismatch exists, clinicians and industry should address the underlying concerns, which may explain these findings.

Not correcting clinically significant astigmatism, for example by prescribing a spherical equivalent, is not a trivial issue. The blur from astigmatism may result in visual discomfort. For example, a study of symptoms due to reading with optically induced uncorrected astigmatism found that participants complained of bilateral headaches (frontal, intraocular, generalized, temporal and occipital), blur and distortion of words, leading to a desire to cease the reading task. ${ }^{8}$ Another study found that even low levels of induced astigmatism, of the magnitude of $1.00 \mathrm{DC}$, resulted in blurred reading materials and slower reading speeds. ${ }^{9}$ Induced astigmatism, particularly oblique astigmatism, may also increase falls risk. ${ }^{9}$ One drawback of studies of induced astigmatism is that the described effects are associated with the short-term experience of astigmatism. However, these findings are consistent with the clinical signs and symptoms of uncorrected refractive errors in real patient populations ${ }^{10}$ and so the results are likely to be indicative of real experience. Not correcting the astigmatism of patients with real astigmatism has been found to result in poorer visual outcomes. ${ }^{10}$ Toric CL correction has been found to result in better visual acuity ${ }^{11-13}$ than spherical CL correction in people with astigmatism. Further, validated patient-reported outcome measures such as the National Eye Institute Refractive Error Quality of Life Instrument (overall score and clarity of vision) ${ }^{10}$ and Convergence Insufficiency Symptoms Survey ${ }^{10}$ also show better outcomes for toric over spherical CL correction in people with astigmatism.

Collectively, the abovementioned studies suggest that the appropriate correction of astigmatism is necessary for comfortable and clear reading vision. Typically, individuals with refractive errors who opt for refractive correction with spectacle lenses have their spherical and astigmatic ametropias corrected with spectacle wear; however, the same may not be true for individuals who select CL refractive correction. Inaccurate astigmatic correction of CL wearers may occur due to a number of reasons. Firstly, there are potentially greater difficulties in the prescription of toric CLs compared with spherical CLs. For example, there may be limitations in the availability of astigmatic powers and meridians (particularly oblique) for different CL designs as stock lenses, ${ }^{11}$ the need to deal with CL rotation, ${ }^{14,15}$ (hence axis of the cylinder) and the potential for resultant differential prism between the right and left eyes in the case of prims or peripheral ballast CL designs in individuals with monocular astigmatism. ${ }^{16}$ With respect to lens rotation and mislocation, oblique astigmatism and withthe-rule astigmatism are thought to be more challenging to correct with CLs than against-the-rule astigmatism due to CL thickness profiles and their interaction with the eyelids on the blink, which may result in poor or unstable vision. ${ }^{17}$

Table I Prevalence of clinically significant astigmatism sorted according to age (youngest to oldest) and axis distribution (with-the-rule, oblique and against-the-rule)

\begin{tabular}{|c|c|c|c|c|c|}
\hline Country, paper & $\begin{array}{l}\text { Subjects } \\
\text { age } n\end{array}$ & $\begin{array}{l}\text { \% With significant } \\
\text { cylinder } \\
\text { (>0.75 DC) }\end{array}$ & With the rule & Oblique & Against the rule \\
\hline Egypt, Sayed $(2016)^{2}$ & $2.05 \pm 1.57$ years $n=307$ & $70 \%$ & $81 \%$ & $13.3 \%$ & $5.3 \%$ \\
\hline $\begin{array}{l}\text { Brazil, Lipener et al } \\
(2006)^{\prime}\end{array}$ & $2-36$ months $n=468$ & $25 \%$ & $75 \%-93 \%$ & $0 \%-8 \%$ & $5 \%-7 \%$ \\
\hline $\begin{array}{l}\text { China, Wang et al } \\
(2014)^{6}\end{array}$ & $2-7$ years $n=2,255$ & $33 \%$ & $84 \%$ & $4 \%$ & $2 \%$ \\
\hline $\begin{array}{l}\text { Singapore, Koh et al } \\
(20 \mid 4)^{3}\end{array}$ & $\begin{array}{l}\text { I996/1997 cohort: } 16-25 \\
\text { years males } n=15,085 \\
\text { 2009-2010 cohort: } 17-29 \\
\text { years males } n=28,908\end{array}$ & $41.3 \%-50.9 \%$ & $51 \%-61 \%$ & $30 \%-31 \%$ & $9 \%-19 \%$ \\
\hline $\begin{array}{l}\text { Australia, Sanfilippo } \\
\text { et al }(2015)^{4}\end{array}$ & $\mid 9-90$ years $n=3,84 \mid$ & $\begin{array}{l}5-20 \text { years: } 9 \% \\
2 I-40 \text { years: } 14 \% \\
4 I-60 \text { years: } 17 \% \\
\geq 6 \text { I years: } 48 \%\end{array}$ & $\begin{array}{l}5-20 \text { years: } 4 I \% \\
2 I-40 \text { years: } 39 \% \\
4 I-60 \text { years: } 35 \% \\
\geq 6 I \text { years: } 20 \%\end{array}$ & $\begin{array}{l}5-20 \text { years: } 18 \% \\
\text { 2I-40 years: } 20 \% \\
\text { 4I-60 years: } 20 \% \\
\geq 6 \text { I years: } 12 \%\end{array}$ & $\begin{array}{l}5-20 \text { years: } 41 \% \\
2 I-40 \text { years: } 41 \% \\
4 I-60 \text { years: } 45 \% \\
\geq 6 I \text { years: } 68 \%\end{array}$ \\
\hline $\begin{array}{l}\text { Korea, Rim et al } \\
(2016)^{5}\end{array}$ & $\begin{array}{l}2008-2012: \geq 5 \text { to } \geq 70 \text { years } \\
n=33,355\end{array}$ & $\begin{array}{l}5-19 \text { years: } 21 \% \\
20-39 \text { years: } 27 \% \\
40-59 \text { years: } 29 \% \\
\geq 60 \text { years: } 56 \%\end{array}$ & $\begin{array}{l}5-19 \text { years: } 70 \% \\
20-39 \text { years: } 55 \% \\
40-59 \text { years: } 27 \% \\
\geq 60 \text { years: } 9 \%\end{array}$ & $\begin{array}{l}5-19 \text { years: } 22 \% \\
20-39 \text { years: } 28 \% \\
40-59 \text { years: } 34 \% \\
\geq 60 \text { years: } 42 \%\end{array}$ & $\begin{array}{l}5-19 \text { years: } 8 \% \\
20-39 \text { years: } 17 \% \\
40-59 \text { years: } 39 \% \\
\geq 60 \text { years: } 50 \%\end{array}$ \\
\hline
\end{tabular}


Secondly, patients themselves may be reluctant to purchase toric CLs due to financial concerns, as toric CLs are generally more highly priced than spherical CLs. ${ }^{18}$ Patients may have had previous adverse experiences with toric CLs such as poor vision due to CL rotation, ${ }^{19}$ difficulty with inserting toric lenses at the correct orientation or even complications such as corneal neovascularization, a complication which has been observed in wearers of older and thicker HEMA lens designs, such as prism ballast toric lenses. ${ }^{20}$

The purpose of this study is to investigate and compare spectacle and CL prescription trends, with an emphasis on astigmatic refractive error prescribing differences for patients who purchase spectacles or CLs in South Korea, as South Korea had a relatively low prescribing rate of toric lenses in

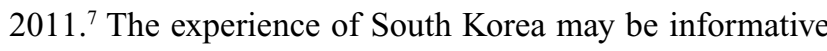
to industry and clinicians of countries with similar prescribing profiles.

\section{Methods}

To address the aims of the study, a retrospective study of patient records of spectacle and CL wearers from a major optical chain in South Korea was conducted. The research was conducted following the tenets of the Declaration of Helsinki, and the research protocol was approved by the Catholic University of Daegu Institutional Review Board. Informed consent was not required, as only de-identified data were obtained. The optical chain provided data from their electronic patient records, which included de-identified information regarding patients' age, gender, prescribed spectacle and/or CL prescriptions. Data were collected for the following four groups of people: 1) the first 10,000 patients who made a purchase of either CLs or spectacles, 2) the first 10,000 patients who purchased spectacles only, 3) the first 10,000 patients who purchased CLs only and 4) the first 10,000 patients who purchased both CLs and spectacles during the 2013 calendar year. The electronic database from which the data were drawn only recorded the prescription that was purchased; therefore, the data of the first three groups will be examined for demographic differences. However, the data of the fourth group will be used to estimate the prescribing gap for toric lenses through a comparison of the spectacle and CL prescriptions of the same individuals at the same visit as they are the only group for which there is assurance that the spectacle and CL prescriptions were both current at the same time. Data were obtained from an electronic database that included data from approximately 190 practices, which were located in all the major cities across South Korea. The spectacle and CL prescriptions in the electronic records were provided by registered optometrists.
The need for toric CL prescription was estimated based on an assumption that spectacle corrections, when adjusted in power for an assumed vertex distance of $12 \mathrm{~mm}$ to CL powers that have a 0.75 difference in power between the principal meridians would indicate candidates that are potentially suitable for toric CL prescriptions, as correction of even low levels of astigmatism have been found to be beneficial. ${ }^{11-13}$

Descriptive analysis was conducted, and chi-square analysis was performed to assess for significant differences in proportions between groups in terms of correction type (spectacles or CLs), gender (male or female), optical correction power and cylindrical axis. Power and axis distribution of both spectacle and CL prescriptions were analyzed. There is more than one way to categorise astigmatic axes. In the present study categories were aligned to be consistent with epidemiological refractive error data ${ }^{5}$; with-the-rule astigmatism was defined as 0-15 and 165-180, against-the-rule astigmatism was defined as axis between 75 and 105, and oblique astigmatism the remaining axes at 16-74 and 164-106.

An estimate of met need for toric CLs and unmet need of toric CLs on the basis of cylinder power was made from the Group 4 data. The met need was defined as the number of eyes that could be prescribed a toric lens with $0.75 \mathrm{DC}$ or greater and were prescribed a toric lens. The unmet need was defined as the number of eyes that could be prescribed a toric lens with $0.75 \mathrm{DC}$ or greater and were not prescribed a toric lens. The toric CL coverage ${ }^{21}(\%)=($ met need $/($ met need+ unmet need) $\times 100$, and the potential prescribing gap (\%) may be defined as 100-coverage. The total need for toric CLs in Group 4 expressed as a percentage may be called $K$.

On the assumption that the percentage of toric CLs prescribed in Group 3 should be the same as the total need for toric CLs in Group $4(K)$, the unmet need for toric lenses may be calculated for Group 3. Coverage and the potential prescribing gap may then be calculated for Group 3 .

To determine if these potential prescribing gaps may be related to axis, Group 4 data were not used as those patients had all bought spectacles and CLs and had identical refractive errors, even if the spectacle and CL prescriptions differed. Instead a comparison of Groups 2 and 3 right eye data is appropriate to assess for statistically significant differences in proportions across the axes and between the groups (spectacle and CL wearers) using chi-square analysis.

\section{Results}

Demographic information is presented to characterize each of the groups in Table 2. It can be seen that 10,000 purchases were made in the first 4 days of 2013. Assuming closure once per month and on all public holidays, it is projected that 
Table 2 Demographic information by gender and optical correction type

\begin{tabular}{|c|c|c|c|c|}
\hline Group & Males:females & Spec: CL & Age bands (\%) & Date range \\
\hline I, First 10,000 purchasers & $\begin{array}{l}\text { Males: } 38 \% \\
\text { Females: } 62 \%\end{array}$ & $\begin{array}{l}\text { Spec: } 59 \% \\
\text { CLs: } 41 \%\end{array}$ & $\begin{array}{l}<2036.0 \% \# \\
20 \leq 4044.2 \% \\
40 \leq 6016.1 \% \\
60+3.6 \%\end{array}$ & January I-4, 2013 \\
\hline 2 , First 10,000 spectacle lens purchasers & $\begin{array}{l}\text { Males: } 57 \% \\
\text { Females: } 43 \%\end{array}$ & $\begin{array}{l}\text { Spec: } 100 \% \\
\text { CLs: } 0 \%\end{array}$ & $\begin{array}{l}<2021.9 \% \\
20 \leq 4046.0 \% \\
40 \leq 6024.3 \% \\
60+7.8 \%\end{array}$ & January I-5, 2013 \\
\hline 3, First 10,000 contact lens purchasers & $\begin{array}{l}\text { Males: } 12 \% \\
\text { Females: } 88 \%\end{array}$ & $\begin{array}{l}\text { Spec: } 0 \% \\
\text { CLs: } 100 \%\end{array}$ & $\begin{array}{l}<2027.9 \% \\
20 \leq 4074.8 \% \\
40 \leq 602.6 \% \\
60+0.08 \% \\
<2043.0 \% \wedge\end{array}$ & January I-8, 2013 \\
\hline 4 , First 10,000 spectacle and contact lens purchasers & $\begin{array}{l}\text { Males: } 18 \% \\
\text { Females: } 82 \%\end{array}$ & $\begin{array}{l}\text { Spec: } 100 \% \\
\text { CLs: } 100 \%\end{array}$ & $\begin{array}{l}20 \leq 4053.7 \% \\
40 \leq 603.2 \% \\
60+0.05 \%\end{array}$ & $\begin{array}{l}\text { January I and April I, } \\
2013\end{array}$ \\
\hline
\end{tabular}

Notes: \#12.5\% of the $<20$-year-olds were 12 years and younger, ${ }^{\wedge} 0.8 \%$ of the $<20$-year-olds were 12 years and younger.

Abbreviations: $\mathrm{CL}$, contact lens; Spec, spectacles.

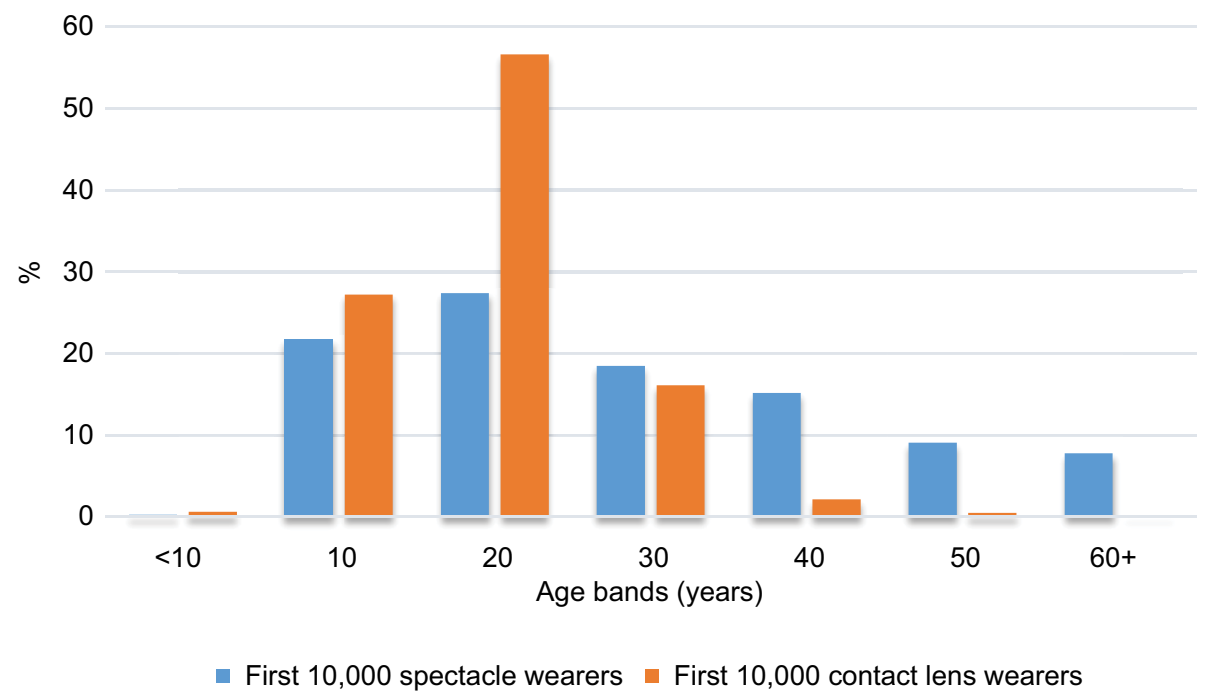

Figure I Age comparison for Group 2 (spectacle) and 3 (contact lens) wearers.

855,000 purchases were made in 2013 . Therefore, the $95 \%$ CIs for the proportional data from the samples, assuming a $50 \%$ proportion, will be $\pm 1 \%$.

Group 1, the first 10,000 purchasers, comprised 59\% spectacle and $41 \%$ CL wearers. There was a statistically significant difference in the proportion of patients by gender between Group 2, the first 10,000 spectacle wearers, and Group 3, the first 10,000 CL wearers $\left(\chi^{2}=4480.36, d f=1\right.$, $P<0.0001$ ), with females making more CL purchases than males. There was a significant difference in the proportions of purchases by type (spectacles or CLs) by age group $\left(\chi^{2}=3246.69, d f=3, P<0.0001\right)$. CL wearers (Group 2) were mostly less than 40 years of age with only a small proportion aged between 40 and 60 years being prescribed CLs (2.6\%-95\% CI 2.4\%-3.0\%) compared with those prescribed spectacles (32.1\%-95\% CI 31.2\%-33.0\%) (Group 3). A more detailed breakdown into 10 -year age bins is provided in Figure 1. 
Type of astigmatism (n)

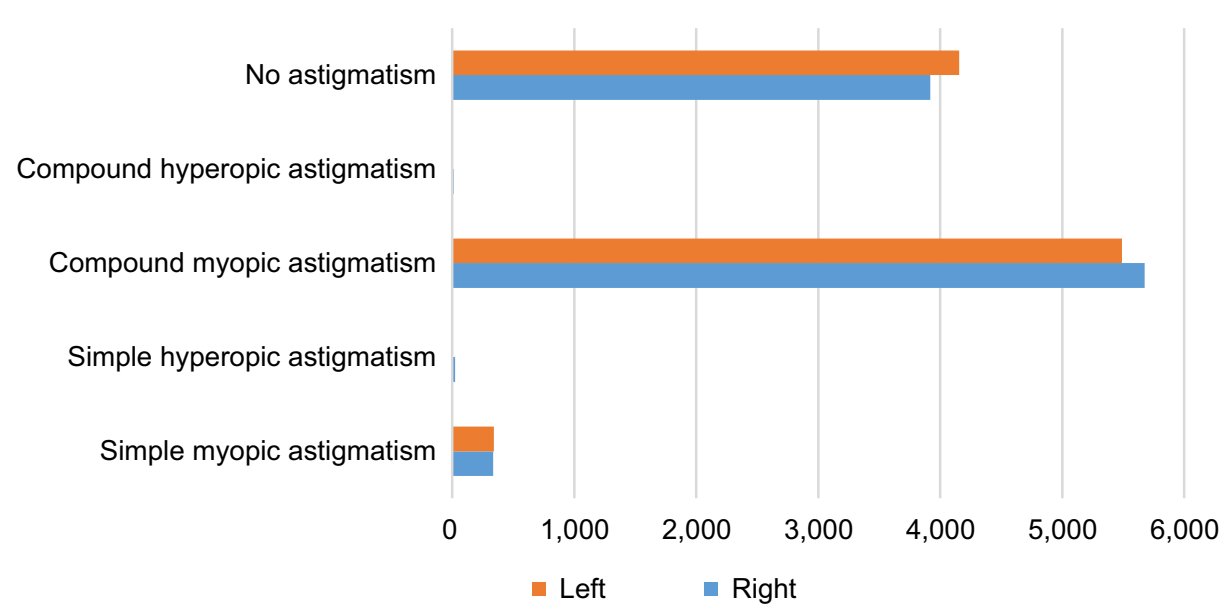

Figure 2 Type of astigmatism in spectacle wearers for right and left eyes (Group 2).

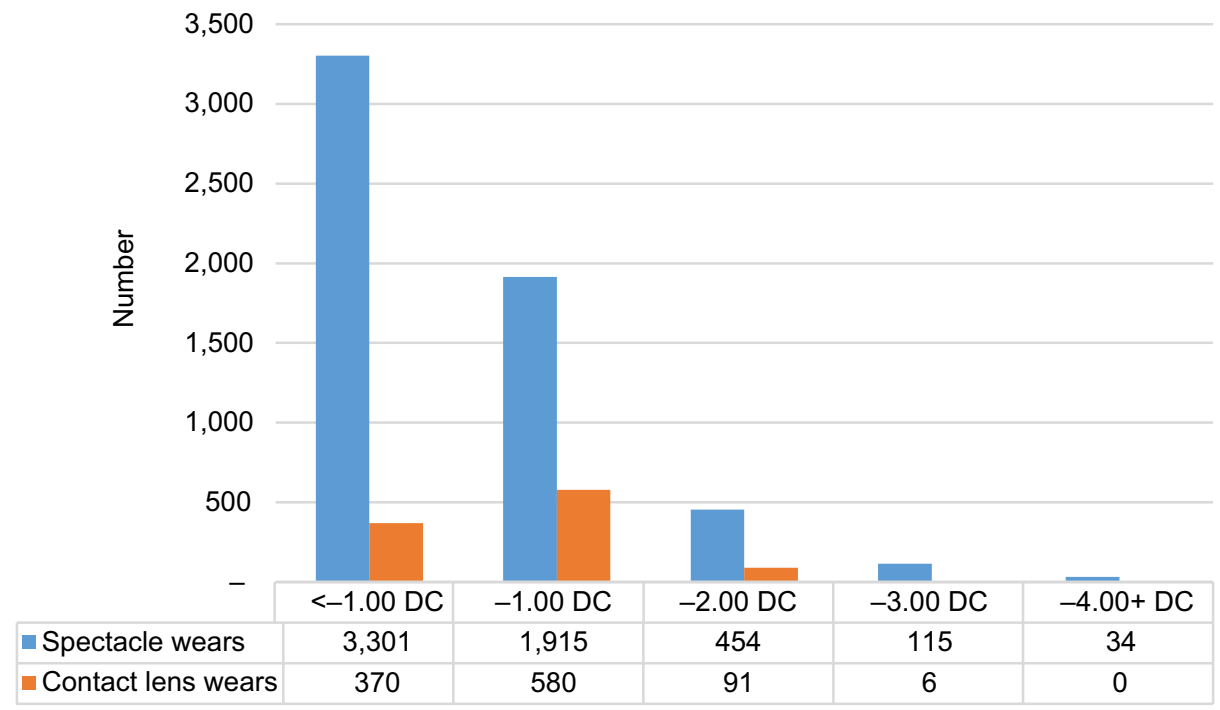

Figure 3 Comparison of cylindrical powers prescribed for Group 2 (spectacle wearers) and Group 3 (contact lens wearers).

As Group 2 is most likely to represent the general population who seek eye care, the type of astigmatism was assessed in this group and found to be mostly compound myopic astigmatism (Figure 2).

With respect to the lens powers ordered, there was a significant difference in the spherical refractive error profile for spectacle and CL prescriptions $\left(\chi^{2}=112.3, d f=3, P<0.0001\right)$. The CL prescriptions had lower proportions of refractive errors of $1.00 \mathrm{D}$ than spectacle lens prescriptions (Figure 3). There was a significant difference in the cylindrical power profile for spectacle and CL wearers $\left(\chi^{2}=216.32, d f=4\right.$, $P<0.0001)$. The majority of spectacle prescriptions had cyl- inder $<1.00 \mathrm{DC}$, with a trend of decreasing prevalence with increasing cylindrical power. By contrast, the majority of $\mathrm{CL}$ prescriptions had cylindrical powers of $\geq 1.00 \mathrm{DC}$, followed by $\leq 0.75 \mathrm{DC}$ (Figure 3). The percentage of prescriptions that contained clinically significant astigmatism was higher for spectacles purchasers (Group 2) $(25 \%, n=2,518)$ than $C L$ purchasers (Group 3) (11\%). The frequency of prescribing was evaluated in $0.25 \mathrm{D}$ steps to assess if there was any skew towards half or full diopter fitting, as found by Young et al, ${ }^{22}$ and this was found to occur only for CL powers in the range -5.00 to -9.50 DS. CL cylinder prescribing showed a bias to $0.50 \mathrm{D}$ steps, but at $-0.75,-1.25,-1.75$ and $-2.25 \mathrm{DC}$. 


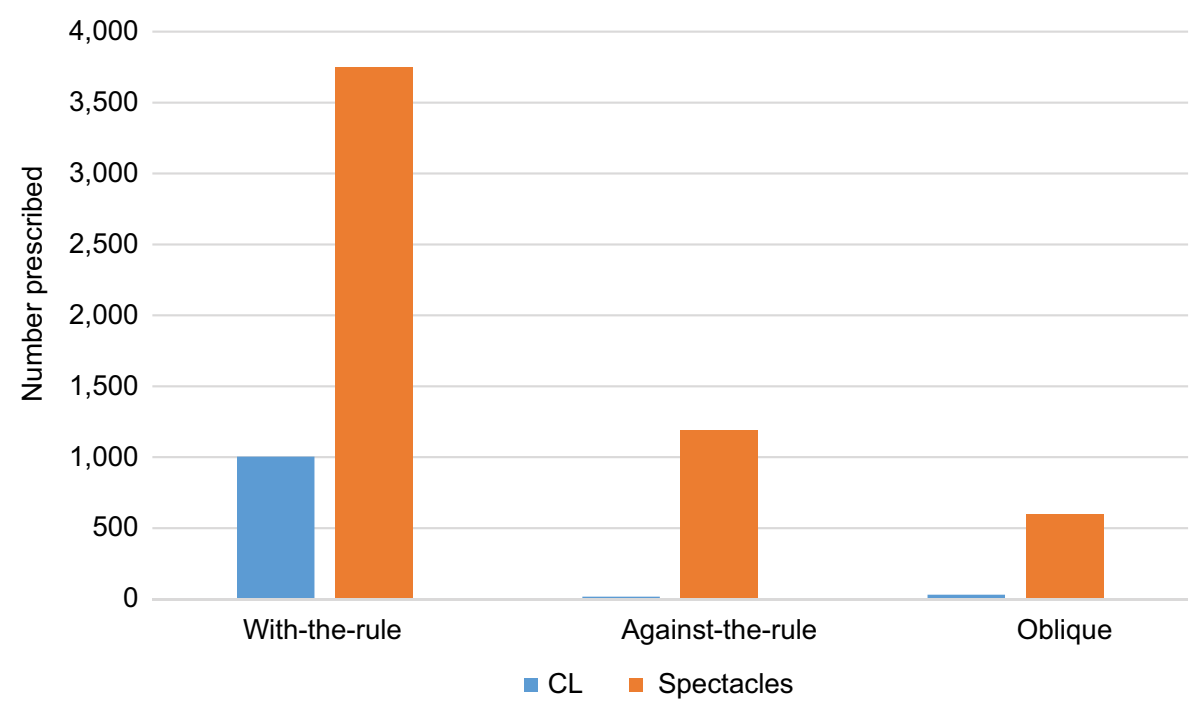

Figure 4 Number of right cylindrical lenses prescribed according to type by axis for CL wearers (Group 3) and spectacle wearers (Group 2). Abbreviation: $\mathrm{CL}$, contact lens.

There was a significant difference in the cylinder axis profile for spectacle (Group 2) and CL (Group 3) prescriptions (Figure 4) $\left(\chi^{2}=357.58, d f=2, P<0.0001\right)$. The $C L$ wearers had a higher proportion of with-the-rule and lower proportion of against-the-rule and oblique axes than the spectacle wearers. The chi-square analysis indicated that within the CL group, the number of with-the-rule axes was $144 \%$ of the expected counts, but oblique and against-the-rule axes were $30 \%$ and $9 \%$ of the expected counts, respectively. This indicates that axis type has an effect on prescribing trends for spectacles and CLs.

There are numerous reasons why people with clinically significant astigmatism may not wish to wear CLs that are unrelated to refractive error profile (power or axis), such as no interest in wearing CLs or finding any kind of CL uncomfortable. The inclusion of Group 4, people who were prescribed both spectacle and toric CLs, allows the further investigation for potential reasons for the apparent shortfall in toric lens prescribing that has been observed between Groups 2 and 3 data, and reported previously in people who wish to wear both spectacles and CLs. ${ }^{7}$

In the Group 4 patients, based on the prescribed spectacle corrections, after correcting for vertex distance, 3,782 right eyes (37\%) and 4,327 left eyes (43\%) could have been prescribed a toric CL with at least $0.75 \mathrm{DC}$; hence, the total need was 8,109 eyes. However, only 1,562 and 1,738 of those right and left eyes, respectively, were prescribed toric CLs; hence, the met need was 3,300. Coverage was calculated as $41 \%$; hence, the unmet need, or prescribing gap on the basis of power, was $59 \%$. The total toric lens need amongst CL wearers (K) was calculated as $41 \%$ on average. On the assumption that the need in Groups 3 and 4 should be similar as they both comprise groups of people who wear CLs, as only 1,020 right toric lenses were prescribed instead of 4,100 (of the 10,000) in Group 3, the estimated coverage for toric lens wear is $25 \%$, indicating a prescribing gap of $75 \%$.

The median (range) of the toric powers that were uncorrected for the right eye was $-1.00(-0.75$ to -4.75$) \mathrm{DC}$, and for the left eye was $-1.00(-0.75$ to -1.75$)$ DC. Right CLs were prescribed with axes exactly corresponding to the spectacle axes; however, in the left lenses, $10 \%$ were prescribed axes 5-10 degrees away, and 5\% were prescribed 10-25 degrees away from the spectacle axes. Where spherical lenses were prescribed instead of toric lenses, the patient's spectacle prescription was mostly with-the-rule. Axes to correct against-the-rule and oblique astigmatism only comprised $4 \%$ and $6 \%$ of the axes, respectively, for the right eye, and $2 \%$ and $2 \%$ of the axes, respectively, for the left eye. The Fisher's exact test did not indicate a significant difference in proportions between those that were fitted with spherical instead of toric lenses or those fitted with toric lenses $(P=0.26)$.

The trends of spherical equivalent CL power distribution for $\mathrm{CL}$ wearers who were not prescribed toric lenses when they had clinically significant astigmatism, and those who were, are presented in Figure 5. Thirty-two percent of patients with clinically significant astigmatism on the basis of toric lens power had clinically significant astigmatism only in one eye, rather than both eyes. However, the proportion of toric CL wearers 
who were prescribed a toric lens in one eye only was about $7 \%$, which is a statistically significant difference in proportions compared with their need $\left(\chi^{2}=18.35, d f=1, P<0.0001\right)$.

\section{Discussion}

The refractive prescribing profile of spectacle and CL wearers in our sample was significantly different. CL wearers were more likely to wear spherical correction or have astigmatic correction for with-the rule astigmatism.

For Group 4, who were prescribed both CLs and spectacles at the same visit, the toric lens need was $38 \%-43 \%$ of lenses prescribed, but spherical lenses were prescribed instead for $41 \%$ of those patients, indicating missed opportunities for toric lens prescription. This agrees with Holden et al' $\mathrm{s}^{23}\left(\mathrm{cited} \mathrm{in}^{24}\right)$ previous estimate that $62 \%$ of all soft lens wearers would require a toric lens prescription if all astigmatism of $\geq 0.50 \mathrm{DC}$ were corrected, or $42 \%$ of all soft lens wearers would require a toric lens if all astigmatism of $\geq 0.75 \mathrm{DC}$ were corrected. The spherical equivalent power of patients who were prescribed spherical CLs showed a trend of being shifted to be slightly weaker in minus power than for patients prescribed toric CLs (Figure 5). The median residual astigmatism when spherical lenses were prescribed instead of toric lenses was approximately 1.00 DC. Within Group 4, axis type was unrelated as to whether or not toric lenses were prescribed. The observed differences between prescribed axes for spectacle and CL prescriptions of the same persons may reflect compensation for mislocation of the $\mathrm{CL}$ orientation in situ. It is important to prescribe for astigmatism, as there is a risk of providing suboptimal vision that may be more noticeable for wearers of both spectacles and CLs, par- ticularly as these corrections are collected at the same visit. It has been found that lapsed toric lens wearers have been found to have lower retention rates when refitted with CLs than lapsed spherical lens wearers, mainly due to dissatisfaction with their vision rather than physical discomfort. ${ }^{25}$ This suggests that prescribers and manufacturers must take care to maximize the vision of their patients, especially those with astigmatism that may be correctable by CLs.

Even if clinicians try to prescribe accurately, limited CL power availability in $0.25 \mathrm{DC}$ steps of power may contribute to suboptimal vision. The prescriptions for CLs were limited to $-0.75,-1.25,-1.75$ and $-2.25 \mathrm{DC}$ despite the spectacle distributions showing that intermediate cylinder powers exist in this population. Further limited CL power availability for sphere powers stronger than 5.00 DS limits prescribing to half and full diopter steps. A previous study has observed that in some populations, practitioners prescribe to half diopter steps apparently from preference. ${ }^{22}$ The current data indicates that the clinicians who prescribed the corrections in the current study did not prescribe in half diopter steps from preference, but due to limitations in CL power availability.

Based on Groups 1-3 findings, with-the-rule astigmatism was over-represented (proportionally) compared to againstthe-rule and oblique axes for the CL wearers in comparison with the spectacle wearers. Oblique astigmatism has been identified as being more problematic to correct with CLs than with-the-rule astigmatism, ${ }^{17}$ which may explain their under-representation. Although with-the-rule astigmatism is thought to be more difficult to fit than against-the-rule astigmatism, against-the-rule astigmatism was more under-

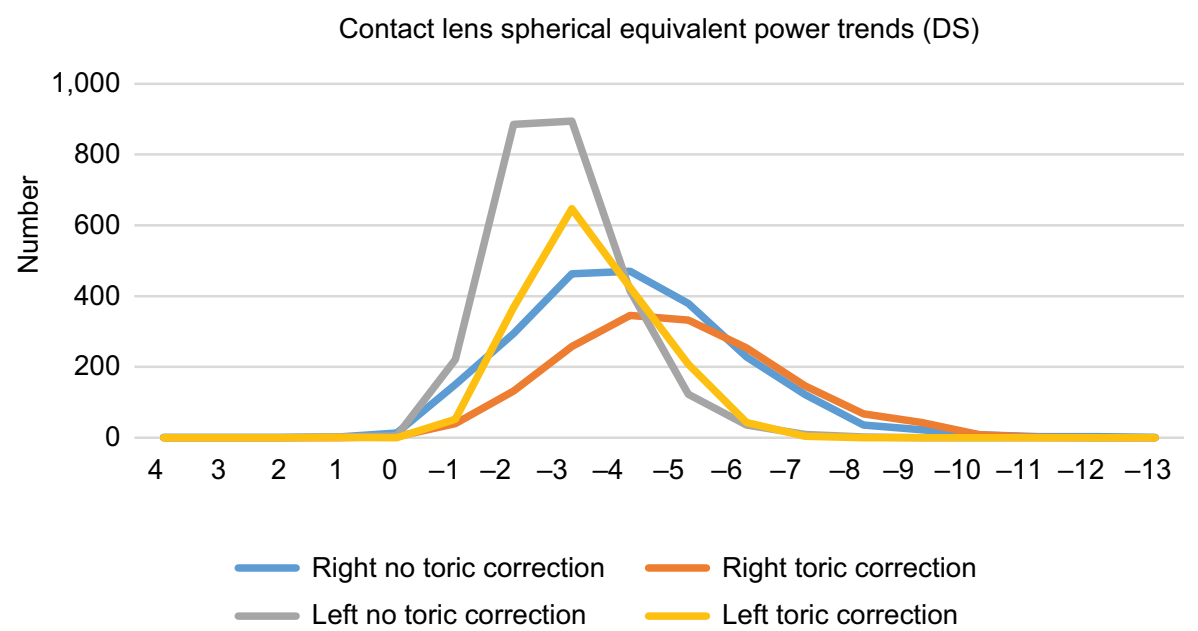

Figure 5 Group 4 spherical equivalent contact lens power distribution for contact lens wearers who were not prescribed toric lenses when they had clinically significant astigmatism, and those who were prescribed toric lenses.

Abbreviation: DS, dioptre sphere. 
represented. Hence, it is unlikely that fitting difficulties account for the differences in the proportions of types of prescribed axes between spectacle and CL wearers. The age differences between the spectacle and CL wearers (see demographic data Table 2, Figure 1) may instead account for the findings. The prevalence of against-the-rule astigmatism is known to increase with age, whilst with-the-rule prevalence decreases, ${ }^{5,26,27}$ hence, the CL wearers, who were predominantly younger, would have had a naturally smaller proportion of people with against-the-rule astigmatism. The over-representation of spherical prescriptions amongst the CL wearers (Group 3) may reflect that spherical lenses were prescribed by optometrists when toric lens could have been prescribed, as was observed in Group 4. Further, because the proportion of monocular toric lens prescriptions is lower than expected based on need, it may be that requiring only one $\mathrm{CL}$ is considered by clinicians when deciding on whether to prescribe spherical or toric lenses. Perhaps the potential for differential prism between the right and left eyes in prism ballast CL designs in individuals with monocular astigmatism is affecting prescribing habits, ${ }^{16}$ or differences in physical sensation/comfort between the two eyes due to differences in lens design. There are CL designs that do not employ prism ballast and they should be considered for patients who have monocular toric CL needs. It is unclear whether the decision to prescribe spherical over toric CLs is related to financial concerns, comfort or patient or practitioner preferences, or a combination of those possibilities.

The demographic finding that CL wearers were mostly younger than 40 years, and more likely to be female, has also been observed in other countries. For example, in Australia the mean (SD) age of CL wearers in the period 2000-2009 was 33.2 (13.6) years, and 65\% were female. In the UK, over a 10-year period from 1996 to 2005, the mean (SD) age of CL wearers was 33 (13) years and 64\% were female. ${ }^{28}$ The current study found that CL wearers were $88 \%$ female and $12 \%$ male. This finding is consistent with 2016 reports that $90 \%$ of CL fits were female in South Korea. ${ }^{29}$ The proportion of gender distributions for South Korea is statistically significantly different from most other countries $\left(\chi^{2}=13.46\right.$, $d f=1, P=0.0002$ in comparison with UK and Australian data) and may indicate that there is scope to increase the percentage of males wearing CLs in South Korea. Higher proportions of females have also been found to wear presbyopic CLs than males, which was thought to be related to greater perceived benefits of the cosmetic benefits of CL wear over spectacles by females more than males. ${ }^{30}$ Similar reasons may explain the trend observed in the present study. The proportion of older people who were found to wear CLs (8\%) was not statistically significantly different $\left(\chi^{2}=2.32, d f=1, P=0.13\right)$ compared with other countries $(16 \%) .{ }^{30}$

The prescribing gap for toric lenses was estimated as $59 \%$ in CL wearers known to have clinically significant astigmatism and wearing both spectacles and CLs (Group 4). This agrees with data from 2007 to $2011^{7}$ that indicated that approximately $20( \pm 7) \%$ of fits were toric lenses, when the world-wide target is $45 \%$, indicating a prescribing gap of approximately $53( \pm 8) \%$. When Group 3 (CL wearers who did not purchase spectacles at the same visit) data were examined, after applying assumptions as described in Methods, the toric lens prescribing gap was estimated to be as high as $75 \%$. As the assumptions applied to the Group 3 data may not reflect reality, so the more accurate estimate of the prescribing gap is from the Group 4 data.

The main limitations of this study are that the data were all obtained from one optical chain; however, it is the largest optical chain and represents a sizeable proportion of the optical market in South Korea so its patients are representative of the population. It also has an electronic database with data that have been consistently collected across the practices. Although large, the electronic database did not include a subjective refraction that was valid for the time of each purchase and contained only the prescribed powers, which limited the kinds of analyses that could be conducted. Another limitation is that the data are from 2013; however, this is appropriate with respect to understanding conditions that impacted the findings at the time of relatively low toric lens fits compared with other countries. ${ }^{7}$ Since these data were collected, the South Korean optical industry has tried to raise the awareness of prescribing toric CLs through the education of clinicians; therefore, a follow-up study of prescribing trends following this educational effort would be useful to understand if the situation has shifted.

\section{Conclusion}

The estimated gap for toric lens prescription amongst CL wearers who have clinically significant astigmatism $\geq 0.75$ DC is about $59 \%$. Toric lens fits may be increased by clinicians considering prescribing toric over spherical equivalent CLs for those patients with clinically significant astigmatism, including patients with monocular toric CL needs. In Korea, both spherical and toric CL fits may also be increased by increasing interest in CL wear amongst males. One way toric CL coverage may be improved is by allowing patients to trial CLs that have the greatest likelihood of producing clear vision through accurate prescription (minimal use of spherical equivalent) by prescribing spherical and cylindrical powers to the nearest $0.25 \mathrm{D}$ rather than $0.50 \mathrm{D}$. Although 
the proportions of prescribed astigmatic axis type differed between spectacle and CL wearers, this appeared to be related to differences in the age-related prevalence of the different types of astigmatic axes of the spectacle and CL wearers.

\section{Acknowledgment}

This work was supported by research grants from Daegu Catholic University in 2017.

\section{Disclosure}

Dong Hwan Noh is employed by the Davich Optical group. The authors report no other conflicts of interest in this work.

\section{References}

1. Lipener C, Munoz EH, Moreira JB, Berezovsky A, Salomão SR, Ventura DF. Refractional astigmatism prevalence and its relationship with grating acuity in children 2 to 36 months of age. Arq Bras Oftalmol. 2006;69(3):365-370.

2. Sayed KM. Analysis of components of total astigmatism in infants and young children. Int Ophthalmol. 2017;37(1):125-129.

3. Koh V, Yang A, Saw SM, et al. Differences in prevalence of refractive errors in young Asian males in Singapore between 1996-1997 and 2009-2010. Ophthalmic Epidemiol. 2014;21(4):247-255.

4. Sanfilippo PG, Yazar S, Kearns L, Sherwin JC, Hewitt AW, Mackey DA. Distribution of astigmatism as a function of age in an Australian population. Acta Ophthalmol. 2015;93(5):e377-e385.

5. Rim TH, Kim SH, et alEpidemiologic Survey Committee of the Korean Ophthalmological Society, et al. Refractive Errors in Koreans: The Korea National Health and Nutrition Examination Survey 2008-2012. Korean J Ophthalmol. 2016;30(3):214-224.

6. Wang X, Liu D, Feng R, Zhao H, Wang Q. Refractive error among urban preschool children in Xuzhou, China. Int J Clin Exp Pathol. 2014;7(12):8922-8928.

7. Morgan PB, Efron N, Woods CA. International Contact Lens Prescribing Survey $\mathrm{C}$. An international survey of toric contact lens prescribing. Eye Contact Lens. 2013;39:132-137.

8. Schubert DG, Walton HN. Effects of induced astigmatism. The Reading Teacher. 1968;21:547-551.

9. Wolffsohn JS, Bhogal G, Shah S. Effect of uncorrected astigmatism on vision. J Cataract Refract Surg. 2011;37(3):454-460.

10. Cox SM, Berntsen DA, Bickle KM, et al. Efficacy of toric contact lenses in fitting and patient-reported outcomes in contact lens wearers. Eye Contact Lens. 2018;44:S296-S299.

11. Morgan PB, Efron SE, Efron N, Hill EA. Inefficacy of aspheric soft contact lenses for the correction of low levels of astigmatism. Optom Vis Sci. 2005;82(9):823-828.
12. Richdale K, Berntsen DA, Mack CJ, Merchea MM, Barr JT. Visual acuity with spherical and toric soft contact lenses in low- to moderateastigmatic eyes. Optom Vis Sci. 2007;84(10):969-975.

13. Cho P, Cheung SW, Charm J. Visual outcome of soflens daily disposable and soflens daily disposable for astigmatism in subjects with low astigmatism. Clin Exp Optom. 2012;95(1):43-47.

14. Momeni-Moghaddam H, Naroo SA, Askarizadeh F, Tahmasebi F. Comparison of fitting stability of the different soft toric contact lenses. Cont Lens Anterior Eye. 2014;37(5):346-350.

15. Tan J, Papas E, Carnt N, et al. Performance standards for toric soft contact lenses. Optom Vis Sci. 2007;84(5):422-428.

16. Sulley A, Hawke R, Lorenz KO, Toubouti Y, Olivares G. Resultant vertical prism in toric soft contact lenses. Cont Lens Anterior Eye. 2015;38(4):253-257.

17. Edrington TB. A literature review: the impact of rotational stabilization methods on toric soft contact lens performance. Cont Lens Anterior Eye. 2011;34(3):104-110.

18. Heiting $\mathrm{G}$ and Segre L. How much do contacts cost? Available from: https://www.allaboutvision.com/contacts/faq/contact-cost.htm. August 2018. Accessed October 2, 2018.

19. Young G, Mcilraith R, Hunt C. Clinical evaluation of factors affecting soft toric lens orientation. Optom Vis Sci. 2009;86(11):E1259-E1266.

20. Chan WK, Weissman BA. Corneal pannus associated with contact lens wear. Am J Ophthalmol. 1996;121(5):540-546.

21. Marmamula S, Ravuri LV, Boon MY, Khanna RC. Spectacle coverage and spectacles use among elderly population in residential care in the south Indian state of Andhra Pradesh. Biomed Res Int. 2013;2013:1-5.

22. Young G, Moody K, Sulley A. Anomalies in the prescribing of soft contact lens power. Eye Contact Lens. 2009;35(1):11-14.

23. Holden BA. The principles and practice of correcting astigmatism with soft contact lenses. Clin Experiment Optometry. 1975;58(8):279-299.

24. Efron N, Morgan PB, Woods CA. Trends in Australian contact lens prescribing during the first decade of the 21st Century (2000-2009). Clin Exp Optom. 2010;93(4):243-252.

25. Young G, Veys J, Pritchard N, Coleman S. A multi-centre study of lapsed contact lens wearers. Ophthalmic Physiol Opt. 2002;22(6):516-527.

26. Asano K, Nomura $\mathrm{H}$, Iwano $M$, et al. Relationship between astigmatism and aging in middle-aged and elderly Japanese. Jpn J Ophthalmol. 2005;49(2):127-133.

27. Collier Wakefield O, Annoh R, Nanavaty MA. Relationship between age, corneal astigmatism, and ocular dimensions with reference to astigmatism in eyes undergoing routine cataract surgery. Eye. 2016;30(4):562-569.

28. Morgan PB, Efron N. A decade of contact lens prescribing trends in the United Kingdom (1996-2005). Cont Lens Anterior Eye. 2006;29(2):59-68.

29. Morgan PB, Woods CA, Tranoudis DO, et al. International contact lens prescribing in 2016. Contact Lens Spectrum. 2017;2017(32):30-35.

30. Morgan PB, Efron N, Woods CA. International Contact Lens Prescribing Survey C. An international survey of contact lens prescribing for presbyopia. Clin Exp Optom. 2011;94(1):87-92.

\section{Clinical Optometry}

\section{Publish your work in this journal}

Clinical Optometry is an international, peer-reviewed, open access journal publishing original research, basic science, clinical and epidemiological studies, reviews and evaluations on clinical optometry. All aspects of patient care are addressed within the journal as well as the practice of optometry including economic and business analyses. Basic and clinical

Submit your manuscript here: https://www.dovepress.com/clinical-optometry-journal
Dovepress

research papers are published that cover all aspects of optics, refraction and its application to the theory and practice of optometry. The manuscript management system is completely online and includes a very quick and fair peer-review system, which is all easy to use. Visit http://www.dovepress. com/testimonials.php to read real quotes from published authors. 